\title{
The Cost of Email Interruption
}

\author{
Thomas Jackson $^{\dagger *}$, Ray Dawson ${ }^{\dagger}$ and Darren Wilson ${ }^{*}$ \\ ${ }^{\dagger}$ Computer Science Department, Loughborough University, Loughborough, Leicestershire, UK, LE11 3TU, email: \\ t.w.jackson@lboro.ac.uk. ${ }^{*}$ The Danwood Group, Harrisson Place, Lincoln, UK, LN6 3DG.
}

\begin{abstract}
The use of email by employees at the Danwood Group was studied and it was found that the interrupt effect from emails is more than generally believed. Employees allowed themselves to be interrupted almost as frequently as telephone calls and the common reaction to the arrival of an email is to react almost as quickly as they would respond to telephone calls. This means the interrupt effect is comparable with that of a telephone call. The recovery time from an email interruption was found to be significantly less than the published recovery time for telephone calls. It is to be concluded, therefore, that while Email is still less disruptive than the telephone, the way the majority of users handle their incoming email has been shown to give far more interruption than expected.

By analysing the data captured the authors have been able to create recommendations for a set of guidelines for email usage within the workplace that will increase employee efficiency by reducing the prominence of interruptions, restricting the use of email-to-all messages, setting-up the email application to display three lines of the email and to check for email less frequently. It is recommended that training should be given to staff on how to use email more effectively to increase employee productivity.
\end{abstract}

\section{INTRODUCTION}

Email is becoming an integral part of the communication structure within organisations and is frequently the basis of collaborative communication between researchers and developers on projects undertaken at multiple locations. Indeed, even when the whole project is undertaken on a single site, email is often regarded as essential to ensure communication and coordination between team members. However, the costs and benefits are not being assessed to show when it is a more effective communication process than traditional methods. Communication is carried out in many different forms, but the common underlying motive of communication is to improve working practices and to increase productivity.

This paper resulted from a study of the communication methods within an organisation that retails office solutions: The Danwood Group. This study is part of a wider research programme to identify the costs and benefits of the IT within the company. The investigation of the benefits of email relative to traditional communication methods forms a study within the company to establish the value of such analysis. The use of IT for communication was chosen for the initial study as the organisation has rising communication overheads with the consequential reduction of employee productivity within all functions. The company expects that a basic understanding gained from this study will provide the data for communication planning and corrective actions for the problems uncovered.

Through communicating we exchange our thoughts, ideas, opinions, feelings with other people, at work, and in every other part of our life. The communication process is so commonplace that it becomes second nature, though by analysing the process it is seen to be much more complex, and much less efficient, than it is normally assumed. By understanding the communication process we can select the optimum communication medium to increase the efficiency of our communication, with benefit to the productiveness of our work. As communication pervades nearly everything we do, even small improvements in the effectiveness and cost of our communication processes can have significant benefits. It is in the interests of management to ensure that the communication process is performed effectively and efficiently and with the minimum disruption to other work.

As new communication methods are introduced into organisations it is important to understand how and why the new media is used (Markus L.M. November 1994), as it is not the media per se that determines communication patterns, but rather the social processes surrounding media use (DeSanctis G. and Poole M.S. 
1994). We still have much to learn about interactions among computer-mediated communication technologies, new organisational forms, and changes in work and communication (Daft R.L. and Lewin A.Y. 1993), but the ability to monitor email now provides organisations with the opportunity to improve communication practices.

To date there has been little research carried out into email usage and the effect of email on the workplace. The authors believe there are a number of reasons for this, such as, the ethics related to monitoring employees at work, or the difficulty of interpreting the data captured. In the authors' earlier research it was found in an established email system that $43 \%$ of emails dealt with were non-business related, which equated to just under two weeks a year spent on non-related work (Jackson T.W., Dawson R. and D. 2000a). The authors still haven't been able to decide if this is undesirable for a company because of lost revenue, or an excellent way to aid team building.

Research carried out by $\mathrm{R}$ Solingen, into communication interrupts showed 15-20 percent of an employee's effort is spent dealing with interrupts and in real terms 15-20 minutes per interrupt (Solingen R., Berghout E. and Latum F. September/October 1998). An interrupt is defined as "any distraction that makes a developer stop his planned activity to respond to the interrupt's initiator". There were 3 types of interrupts defined, personal visits, telephone calls and emails. Personal visits and telephone calls caused 90 percent of all interrupts and email caused the rest. The results showed the effort spent on interrupts required approximately 20 minutes for each occurrence, including the time spent handling the interrupt, and that the average developer receives three to five interrupts per day. This consumes roughly 1 to 1.5 hours per day of the developers time. DeMarco reported that the recovery time after a phone call interruption is at least 15 minutes, thus increasing the amount of time spent on interrupts a day (DeMarco T. and Lister T. 1987). So far there has been little empirical research into how long it takes to recover from an email interrupt. This could be because of the perception of email as a minimal interrupt. DeMarco suggests that the only difference between a phone call and an electronic mail message is that the phone call interrupts and the e-mail does not as the receiver deals with the email at their own convenience (DeMarco T. and Lister T. 1999). The author's research findings in this paper show there is an interrupt recovery time for email and the majority of email users answer email just as quickly as the telephone. The paper also highlights natural communication patterns during the day that could be used to enhance employer productivity by reducing the number of interrupts and employee receives.

\section{THE AFFECTS OF MONITORING}

In an early, 1927-1933, productivity study in Western Electric's Hawthorne plant near Chicago researchers discovered that their own presence affected the outcome of the research. In determining the effects of various environmental parameters on productivity, the researchers tried raising the light level, and they noted that the productivity went up. Then they tried lowering the light level, and they noted that productivity went up higher still. In this case, so long as the study was in progress, productivity increased. The term "Hawthorne Effect" was coined to define the influence of the researcher's presence on the outcome of the study, which was their attention to the employees, increased employee productivity (Mayo 1933).

It was important that the Danwood Group employees did not know they were being monitored as this could have affected the results of this interrupt study. Early research carried out by the authors, at the Danwood Group at Lincoln in the UK, showed that the employees' performances changed when they thought they were being monitored. At the time of the research, the Danwood Group had no email policies to restrict the employees, however the users were made aware that the subject line of their email was being recorded for research purposes. In order to record the metrics a special email application (Figure 1) 'The Danwood Mail', was written by one of the authors to analyse the users activities whilst using the package for communication. The program recorded more than just the subject line and actually recorded (Jackson T.W., Dawson R and D 1999): -

- how many words were in a message

- how long it took the user to read or compose the email

- the subject of the message as well as the subject line

- the recipient

- the sender

- the time and date the email was sent / received 
After a week of monitoring, the employees using the email application began leaving the subject line blank. In some cases the subject line was only left blank when the email was non-business related. Monitoring clearly influenced the employees in making them find ways of disguising their activities.

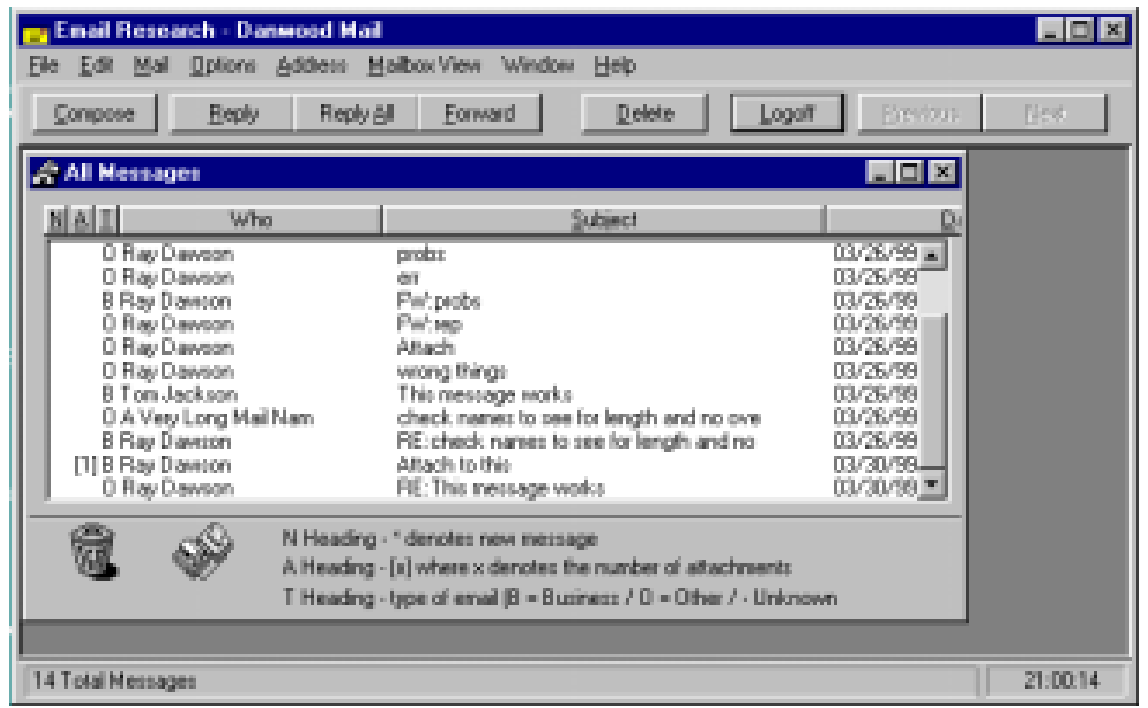

Figure 1 - The Danwood Mail Application

As part of this research it was decided that the employees would not be told about the monitoring taking place as it could affect the results, as it did in the subject line research (Jackson T.W., Dawson R and D 1999). This research was possible as each member of staff had signed the rules and regulations in the company handbook, which permitted the company to monitor electronic communication. Even so, in order to make the research deliver on its potential, management had to be perceptive and secure enough to remove themselves from the immediate monitoring process. That meant the data on individuals was not passed up to management. Only the overall figures were reported to management after the research had been completed. In taking these measures the authors believe they followed the code of conduct of the British Computer Society (British Computer Society 2000).

This concept is a hard one to accept for many managers. They reason that they could use the data to do some aspects of their work more effectively, such as targeting promotion, or even firing. Their company has paid to have the data collected, so why shouldn't it be made available to them? However, if the individual confidentiality had been compromised, the data used against even one individual would have brought the entire data collection scheme to an abrupt halt (DeMarco T. and Lister T. 1999). It is also important to the employees to know another employee within the same company did not carry-out the monitoring. As a full time PhD student at Loughborough University, Jackson had an independent status that was more acceptable to the employees being monitored. This independence is likely to give more accurate results if employees know that information about individuals will not, except in extreme circumstances, be passed on to their managers. It is suggested that other companies would benefit from contracting any monitoring of employees' use of e-mail and the Internet to an independent outside body.

\section{RECORDING THE METRICS}

There were numerous ways the interrupt recovery time metrics could have been recorded. The most obvious way was to record the employees at their desk, carrying out various activities and capturing them on a camcorder. Unfortunately the Danwood Group board of directors deemed this method inappropriate. Another possibility would be to have an actual person watching the employee at their desk from a distance. This method would have probably produced distorted results due to the employee knowing they are being monitored through the constant presence of the monitor (Mayo 1933). The last option considered was to use computer software to monitor the employee. A number of different applications were reviewed to find the most appropriate to record interrupt recovery times. These included, Windows Virtual Network Computing (WinVNC), Back Orifice 2000, 
Lotus SmartCAM, I-SPY and Windows Ranger (Richardson Tristan 1998), (DilDog 2000), (Lotus 2000), (Visionsoft 2000), (Sentinel 2000). Many had a number of restrictions, such as, lack of reliability, no access to the monitoring source code, inappropriate system tray icons, too slow or excessive amounts of media required to record an employee at work for a full day. It was decided that WinVNC would be used alongside a video recorder to record employee activities throughout the day.

WinVNC is a remote display system that allows viewing of a remote computer 'desktop' environment, not only on the machine where it is running but also from anywhere on the Internet and from a wide variety of machine architectures (Cambridge 2000). WinVNC was set-up on both the client and server side to allow monitoring of the employee's machines remotely. The original WinVNC program was modified slightly by one of the authors to remove the icon shown in Figure 2 from the system tray. With the icon removed the employees would not know when they were being monitored. The server side had a video recorder attached to the computer, to record all the employees' activities on the screen to videotape.

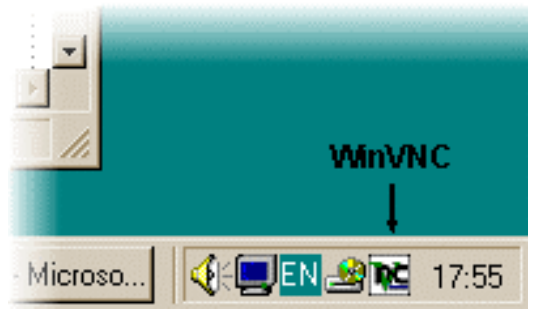

Figure 2 - Shows the WinVNC icon that was later removed from the system tray

At the same time individual employees were being monitored, every employee using email at the Danwood Group was also being monitored for the frequency of individual email collections from the server. One of the authors developed a program that monitored the email server to determine when employees picked up their email. The simple program was written in Visual Basic and recorded the name of the employee, the time and date the employee downloaded email from the server to their local machine.

\section{EMAIL INTERACTION ANALYSIS}

A total of 15 employees were monitored over 28 working days, which led to over 180 hours of videotape recordings. Various types of employees were monitored, such as clerks, programmers and managers. All the employees email interactivity was recorded and analysed as well as the activities leading up to and after the email interruption. The definition of an email interrupt is any email distraction that makes an employee stop their planned activity. The recovery time was calculated by recording the amount of time that it took an employee to return to their work at the same work rate at which they left it. This required an element of judgement by the person reviewing the recorded material. However, there was usually a fairly clear point where the user ceased to move the mouse around the screen and jump between screens trying to pick up their train of thought and the production of useful work. Although this may be regarded as a rather inexact measure, in fact, the authors believe that in reality interpretation of the activities by different people would not have given any real difference in the results.

The graph shown in Figure 3 shows the average number of email file collections a day per employee. The figures are distorted due to the number of employees infrequently using the email system. Out of 267 employees downloading email files from the server, only $40 \%$ of them were frequent email users. The program only recorded successful email downloads and not the attempts made to check if emails were on the server for that individual employee. Even so, on average there were 2 successful email file downloads a day, which could contain one or more emails. The frequency of email downloads highlighted the fact that the majority of employees have their email application set to check for email every 5 minutes.

Out of the entire employees monitored 70\% of them used Microsoft Outlook 2000 and 30\% used Microsoft Outlook 97. All the employees had a new email arrived icon appear in the system tray when new email arrived and $57 \%$ of the employees also had a new email arrived pop-up dialogue box appear. 
It took the average employee an average of 1 minute 44 seconds to react to a new email notification by opening up the email application. The majority of emails, 70\%, were reacted to within 6 seconds of them arriving and $85 \%$ were reacted to within 2 minutes of arriving. The time it takes the average employee to recover from an email interrupt and to return to their work at the same work rate at which they left it, is on average 64 seconds.

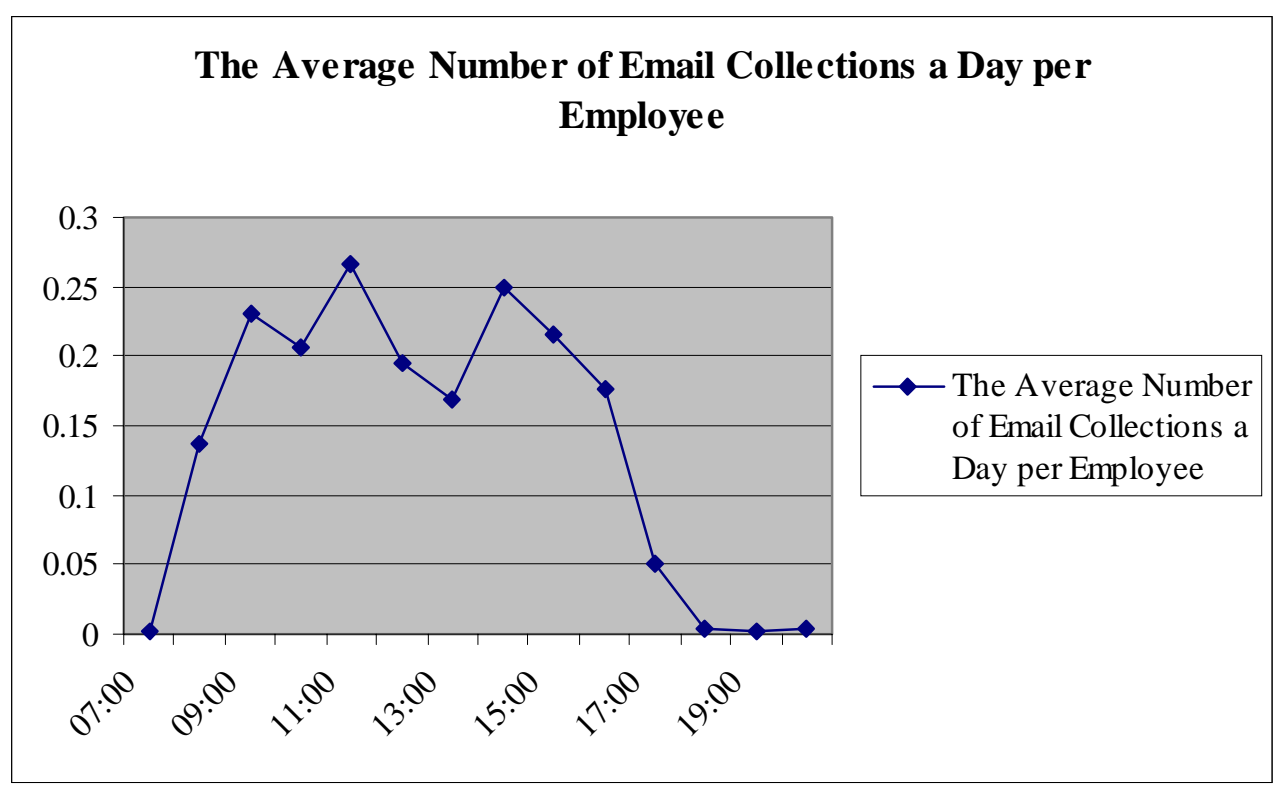

Figure 3 - The Average Number of Email File Collections a Day per Employee

Through analysing individual employees a number of good email practices emerged and through combining these practices and getting employees to adopt them it could increase employee productivity and aid in better interrupt handling. For example, a number of employees would only read their inbox when new email arrived to see whether the email was worth reading. They did this by being able to see three lines of the email, the subject line and the sender. This saved the employee time because many emails, especially junk emails, were deleted without even opening them because the employee could determine the nature of the email by the 3 lines of email on display. Another time saving practice was to use the new email icon located in the system tray to access the newly arrived email. It may seem simple, but a number of employees minimised all the applications to get to their email application, which in some cases took sometime. Whilst monitoring there has also been some strange habits which have been captured, such as, one employee would spend long amounts of time writing nonbusiness emails, send them and then later that day spend even longer re-reading what had been sent.

\section{CONTROLLING COMMUNICATION INTERRUPTS}

There has been various remarks made about email and whether it has an interrupt recovery time associated with it, as the receiver of an email is perceived to deal with it at their own convenience (DeMarco T. and Lister T. 1999), (Zijlstra Fred R.H. 1999), (Solingen R., Berghout E. and Latum F. September/October 1998). This study has shown that $70 \%$ of emails dealt with were viewed within 6 seconds, which is quicker than letting the phone ring three times. Only the very small minority of employees would let the new email go unattended until they had come to a point where it was convenient to stop work and attend to the email. It is difficult to tell if the initial distraction of a new email arriving, either by sound, new email icon in the system tray or the email pop-up dialogue box appearing, does effect the employee because it is difficult to tell what someone is thinking. After the employee has been told about the new email and chooses not to respond, might they be 
thinking, "I wonder who has sent me an email"? It is like being sent an interesting parcel through the post and having to resist the temptation not to open it until the current job has been finished.

The graph in Figure 3 shows the number of email files downloaded during the day per employee, where an email file might contain one or more emails. Currently the Danwood employees do not receive excessive amounts of emails a day. If the number of emails a day were to increase, the way the majority of email applications are set-up to check for email every few minutes would cause an increase in the frequency of interruptions and have a knock on effect of reducing employee productivity. Figure 3 also shows that the peak time for downloading email files from the server is at 11:30am and 14:30. Earlier research carried out by the authors showed that email application interactivity peaked at 8:30am and 16:30 as shown by Figure 4 (Jackson T.W., Dawson R and D 1999).

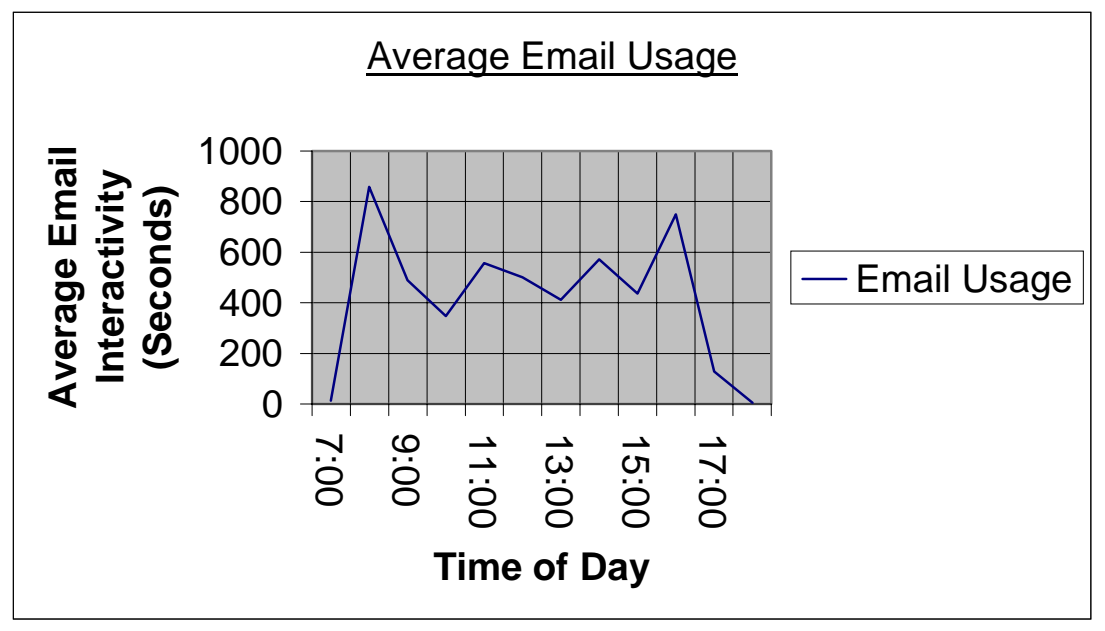

Figure 4 - Email usage throughout the day

(The graph is measured in email interactivity, where email interactivity is classed as a user reading or composing a message including reply, reply all and forwarding).

The smaller peaks in Figure 4 at 11:30am and at 14:30 compliment the peaks in Figure 3. These two graphs suggest that there are four natural communication periods during the day in which companies could experiment and encourage the majority of communication to take part, to help reduce employee interrupts and to reduce the risk of message fatigue (Zijlstra Fred R.H. 1999).

DeMarco and Lister have described the high impact of phone calls in engineering environments: developers routinely receive 15 telephone calls a day, which can make the whole day non-productive (DeMarco T. and Lister T. 1999). While the benefits of email are not as good as expected as a result of the lost time through non business use (Jackson T.W., Dawson R. and D. 2000b), the comparison shows that email is a more effective way of communication than other mediums, in terms of the cost of interrupt recovery time. With the interrupt recovery time for a telephone call at 15 minutes and for an email just over a minute, there is nearly a saving of 14 minutes per communication interruption.

This research has, however, shown that email messages do have some disruptive effect by interrupting the user - more than is generally assumed. It is commonly believed that because a user can read emails in their own time whenever it is convenient the interruption is negligible (DeMarco T. and Lister T. 1999), (Zijlstra Fred R.H. 1999), (Solingen R., Berghout E. and Latum F. September/October 1998). In practice, however, this research has shown that the majority of employees respond to email within 6 seconds, which is similar to the response to a telephone and that the majority of employees enable such interruptions every five minutes. While the recovery time does seem to be less for an email, at 64 seconds it is nevertheless significant when accumulated over a whole day. 


\section{RECOMMENDATIONS FOR BETTER HANDLING OF INTERRUPTS}

It is clear from the observations made that many employees could reduce the time lost through interrupts through simple changes of practice. The authors were therefore able to make recommendations to the company that would allow more effective and efficient use of email, which in turn should make employees more productive. These recommendations given below are based only on the experience of the Danwood Group and therefore can only be considered to be applicable to that company. However, informal enquiries of other companies suggest that the experience at Danwood is not likely to be unique and so it is believed that other companies would also benefit from putting these recommendations into practice.

Most email applications allow different means of notifying the user of incoming email. These different means can give different levels of intrusion, as some are easier to ignore than others. For example a prominent sound accompanying a pop up dialog box that requires a response, has a far more intrusive effect than a small icon that appears in one corner of the screen, yet the user is just as aware of the incoming email whichever is used. A less intrusive notification may encourage users to respond in their own time at a moment which is more convenient for them as it will give less of an interruption to their concentration on the job in hand.

It was notable that many of the email messages employees received were not really relevant to for them. This usually resulted from an email sent to all employees. This was particularly true when employees used a reply-to-all message when the whole company received the message yet it was often only useful to one or two individuals. To reduce this problem employees should be encouraged to restrict their use of email-to-all messages, and especially reply-to-all messages. This may be achieved through better education and training on the use of email. A further encouragement may be to provide more targeted user groups to allow employees to be more selective about who they contact.

The employees who used the facility to display the first three lines of each message were able to make more effective use of their email monitoring activity. This should be a practice all employees should be encouraged to adopt. If all employees used this facility it would reduce the effect of the widespread interruptions caused by email-to-all messages.

Although many employees set their email applications to check for email every five minutes, the nature of email means that it is unlikely to matter if an employee waited a little longer. It would be more productive to the user if the email was checked at an interval when interrupts would be less frequent and possibly even beneficial. Many people find that long periods of concentration on one single task reduces their effectiveness and for that reason it can be beneficial to take a break and think about something else for a few minutes. The length of time a person can effectively concentrate on one task will vary from person to person but typically a break after 45 minutes or so is likely to be beneficial. This gives an indication on how long an interval would be desirable for email interrupts. If employees set their email applications to check for email no more frequently than every 45 minutes (or whichever interval they find most suitable for themselves) then the interruption that does take place is clearly less disruptive and could even have a beneficial effect.

During the study it was noticeable that none of the employees monitored used message rules within their email application. If rules are applied to incoming email, the email can be delivered to a predetermined folder, which aids in the processing of email. For example, setting up message rules to send all news group email to individual news group folders can help determine if the incoming email is urgent, because generally information gained from news groups does not require immediate attention. Some training on the use of message rules and separate folders could enable users to make better use of their email application to categorise and prioritise email so they can make more effective use of the time spent handling incoming messages. 


\section{CONCLUSION}

This research has found that the interrupt effect from emails is more than generally believed. Employees at the company studied allowed themselves to be interrupted almost as frequently (every 5 minutes) as with telephone calls. The common reaction to the arrival of an email is not to delay response to a time that is more convenient to the user but to react within 6 seconds, again almost as quickly as they would respond to telephone calls. This means the interrupt effect is comparable with that of a telephone call. The recovery time from an email interruption is, at 64 seconds, significantly less than the published recovery time for telephone calls. While this gives a significant reduction in recovery time, with users receiving more and more emails the accumulative effect is still likely to be significant. It is to be concluded, therefore, that while Email is still less disruptive than the telephone, the way the majority of users handle their incoming email has been shown to give far more interruption than expected.

By analysing the data captured from the employees interacting with the email application and how they dealt with the frequency of interrupts, the authors have been able to create recommendations for a set of guidelines for email usage within the workplace that will increase employee productivity:

1) Reduce the prominence of interruptions through turning off the new email alert dialogue box and email sound alerts.

2) Restrict the use of email-to-all messages, and in particular reply-to-all messages. The use of more targeted email user groups may assist in this respect.

3) Set-up the email application to display in the inbox the sender, the subject and three lines of the email so the recipient can quickly determine if the email requires immediate attention.

4) Set-up the email application to check for email at no less than every 45 minutes.

5) Introduce training to all staff on how to use email in areas such as, setting email priority, email house keeping with message rules, effective use of the user groups and address books, constructing better structured emails

This research has shown the value of measuring communication processes. The analysis of email has enabled the effect on employee time to be quantified and has given some surprising results. This has lead to a series of recommendations that will enable the Danwood Group to make better use of email communication and increase employee productivity. The implication for managers in other companies is that if their own employees have similar practices in using email then the company would also benefit from following these recommendations.

\section{BIBLIOGRAPHY}

British Computer Society. 2000. "British Computer Society Code of Conduct.". http://www.bcs.org.uk/aboutbcs/coc.htm.

Cambridge, AT\&T Laboratories. 2000. "Windows Virtual Network Computing.”. http://www.camorl.co.uk/vnc/winvnc.html: AT\&T Laboratories Cambridge.

Daft R.L., and Lewin A.Y. 1993. "Where Are the Theories for the 'New' Organizational Forms?" Organizational Science 4:I - IV.

DeMarco T., and Lister T. 1987. Peopleware: Productive Projects and Teams. New York: Dorset House.

DeMarco T., and Lister T. 1999. Peopleware. Productive Projects and Teams 2nd Ed. New York: Dorset House Publishing Company.

DeSanctis G., and Poole M.S. 1994. "Capturing the Complexity in Advanced Technology Use: Adaptive Structuration Theory." Organizational Science 5:121 - 147.

DilDog. 2000. "Back Orifice 2000." . http://www.bo2k.com/indexdownload.html: Cult of the Dead Cow.

Jackson T.W., Dawson R, and Wilson D. 1999. "Improving the Communications Process: The costs and effectiveness of email compared with traditional media.” Pp. 167 - 178 in INSPIRE - Training and Teaching for the understanding of Software Quality. Crete.

Jackson T.W., Dawson R., and Wilson D. 2000a. “The Cost of Email Within Organisations.” Pp. 1093 - 1094 in Challenges of Information Technology Management in the 21 st Century. Alaska. 
Jackson T.W., Dawson R., and Wilson D. 2000b. "E-Communication Analysis: The Cost of an Internal Email Messaging System within Organisations.” Pp. 129 - 140 in Re-Technologies for Information Systems Preparing to E-Business. Zurich.

Lotus. 2000. "Lotus ScreenCam.” . http://www.lotus.com/home.nsf/welcome/screencam/: Lotus.

Markus L.M. November 1994. "Electronic Mail as the Medium of Managerial Choice." Organizational Science 5:502 - 525.

Mayo, E. 1933. The Human Problems of an Industrial Civilization: New York: Macmillan.

Richardson Tristan, Stafford-Fraser Quentin, Wood Kenneth R., Hopper Andy. 1998. "Virtual Network Computing." IEEE Internet Computing 2:33-38.

Sentinel. 2000. "Windows Ranger." . http://www.rangersuite.com/products/win_ranger/winr_functions.htm: Sentinel Products.

Solingen R., Berghout E., and Latum F. September/October 1998. "Interrupts: Just a Minute Never Is." IEEE Software 15:97 - 103.

Visionsoft. 2000. "I-SPY.” . http://www.visionsoft.com/products/ispy.htm: Visionsoft.

Zijlstra Fred R.H., Roe Robert A., Leonora Anna B., Krediet Irene. 1999. "Temporal factors in mental work: Effects on interrupt activities." Journal of Occupational and Organizational Psychology 72:163-185. 